\title{
DIGITAL RESTORATION RESEARCH AND THERR-DIMENSIONAL MODEL CONSTRUCTION ON XIEQIQU
}

\author{
Gao Ming ${ }^{\mathrm{a}}$, Piao Wenzi ${ }^{\mathrm{a} *}$, Guo Jing ${ }^{\mathrm{a}}$
}

åBeijing Re - Yuanmingyuan Company Limited, 100085, Beijing, China - (gaoming, piaowenzi, guojing)@thid.cn

KEY WORDS: Xieqiqu (Harmonious Wonder), Site Features, Historic Archival Resources, Digital Restoration, 3D Modelling

\begin{abstract}
:
As the Baroque style complex in Yuanmingyuan (Old Summer Palace), Xiyanglou (Western Buildings) carries a unique history of the imperial resort. The significance of its restoration has drawn much attention from home and aboard in the field of cultural heritage conservation. Yuanmingyuan Digital Restoration Research Project was officially launched in 2013. Five out of the thirteen scenes in Xiyanglou, namely Xieqiqu (Harmonious Wonder), Haiyantang (Hall of National Peace), Fangwaiguan (Belvedere), Xushuilou(Water Supply Building) and Guanshuifa (Throne to observe water displays), have been studied and restored digitally within the first two years of the project. Among all the scenes in Xiyanglou, Xieqiqu is the first European-style palace and the first scene to be studied in the Digital Restoration Research Project. The 3D reconstruction of the site is based on the current-day survey of the ruins in combination with the historic archival research. Taking Xieqiqu as a case, this paper introduces the digital restoration methodologies, progress and achievements of Yuanmingyuan Digital Restoration Research Project.
\end{abstract}

\section{INTRODUCTION}

Yuanmingyuan (The Old Summer Palace) Archaeological Park is located in the west suburb of Haidian District in Beijing. The site was first constructed in 1707 , consisted of more than 100 scenic spots in its heyday, including a series of gardens such as Changchunyuan(Garden of Eternal Spring), Qichunyuan (Garden of Splendid Spring), Xichunyuan (Garden of Prosperous Spring), Chunxiyuan (Court of the Spring Glory). Among them was the Xiyanglou scenic region. Drew reference from the western hydraulic system, the complex stood as a witness to the splendid cultural exchange between the east and the west over the course of history. Xiyanglou is located at the north tip of Changchunyuan. Its construction began in 1747 and completed in 1783. The complex consisted of over a dozen of Western-style buildings and gardens in a "T" shape layout, stretched $860 \mathrm{~m}$ on the east-west axis. The west end of the site was $320 \mathrm{~m}$ in the north-south direction and $70 \mathrm{~m}$ wide. The site covered an approximately 8 acres of land in total. It was designed and constructed collaboratively by Jesuit missionaries worked for the Imperial Court, Giuseppe Castiglione and Michel Benoist, and the Chinese craftsmen. The entire scenic region, including buildings, fountains, sculptures, and gardens, were built in Baroque and Rococo style using traditional Chinese construction techniques. With an emphasis to showcase the spectacular western hydraulic system, Xiyanglou was the first large scale introduction of the Western garden and architectural style into the Imperial resort. In 1860, British and French troops plundered and burned Yuanmingyuan. Xiyanglou could not escape from its doomed fate. After a few more disasters over the course of history, the site had been severely damaged and was reduced to the ruin today.
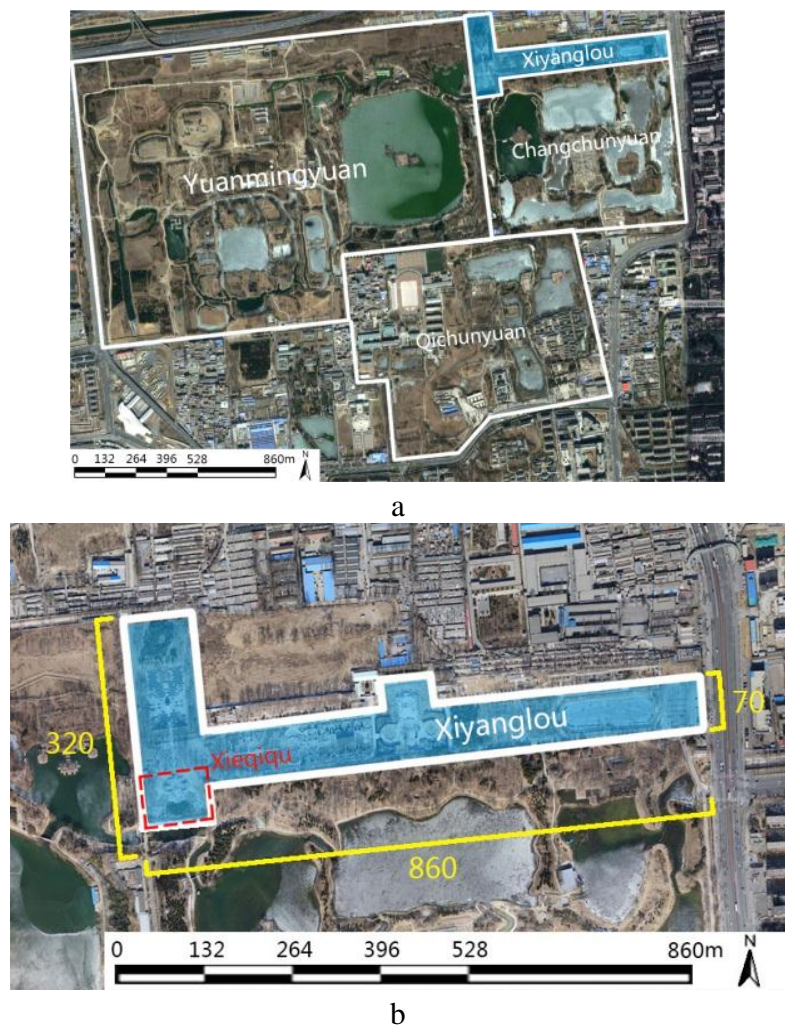

Figure 1. a. Yuanmingyuan; b. Xiyanglou

The scenic region of Xieqiqu covers an area of $9956 \mathrm{~m}^{2}$ in total with $235 \mathrm{~m}^{2}$ of the land taken up by the buildings. The architectural layout was in the form of a semi-arc. The main building consisted of three levels. The ground level had seven bays, flanked by a semi-circle podium in the front and a three-

\footnotetext{
* Corresponding author
} 
bay porch at the back. The second floor also had seven bays, while the top floor had three. Curved corridors with nine bays in length extended from both east and west side of the main building; each had a two-storey octagon music pavilion attached at the end. Columns in Xieqiqu were made by bluestone in the form of Classical Doric Order. The roofs were covered with glazed tiles. The butterfly staircases at the south provided direct access to the patio on the second floor. At the center of the courtyard in front of the main building was a large multifoil fountain. There was another barbed quatrefoil fountain located on the north side of the main building.

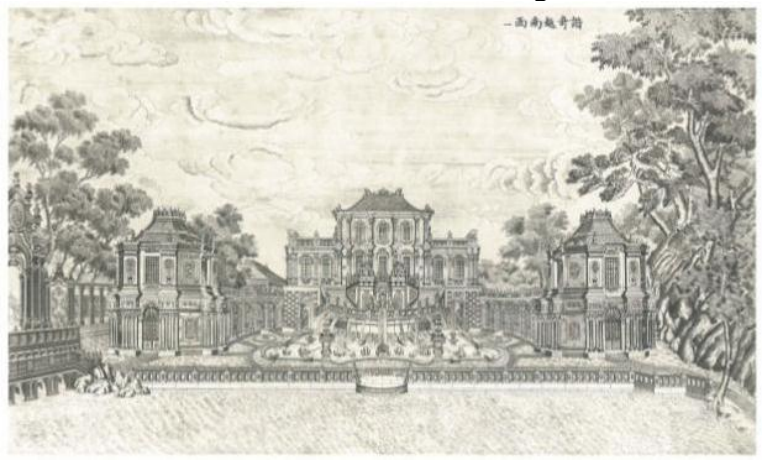

Figure 2. Copperplate etching of Xieqiqu, DaihengGuo and Yan $\mathrm{He}, 2010$

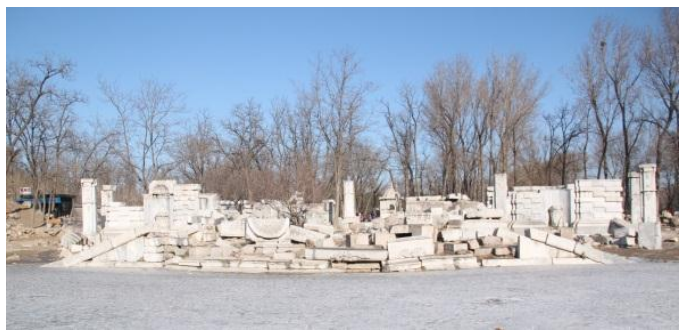

Figure 3. Ruins of Xieqiqu

\section{XIYANGLOU DIGITAL RESTORATION RESEARCH 2.1Data Acquisition, Classification \& Analysis}

The majority of the remains of Xiyanglou are immovable artefacts. Yuanmingyuan Administration made an attempt in the 1980 s to restore and reassemble the fragments. However, due to technical and site limitations, the restoration remained incomplete, at the same time created challenges for future data acquisition and classification. In order to optimize the accuracy and completeness of the digital data, four different techniques were deployed during the information acquisition stage: Aerial Photography, Laser Scanning, Total Station and Manual Recording. The exact measurement, structure and material property of the source object were meticulously reflected on the 3D model, to represent and share the proper heritage information.

The data acquisition and classification of Xieqiqu counted a total of 800 stone components on site. 53 pieces of stone elements with distinctive characteristics were identified. Among them, 47 pieces were catalogued in the database with their exact location marked correspondingly on the copperplate etchings and the aerial photographs.

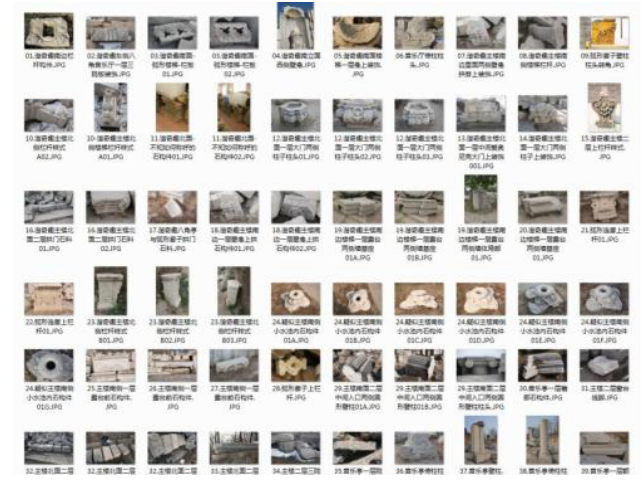

a

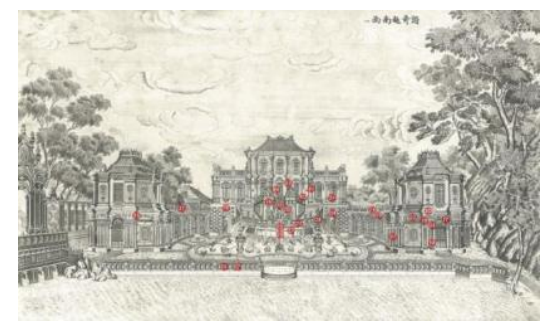

b

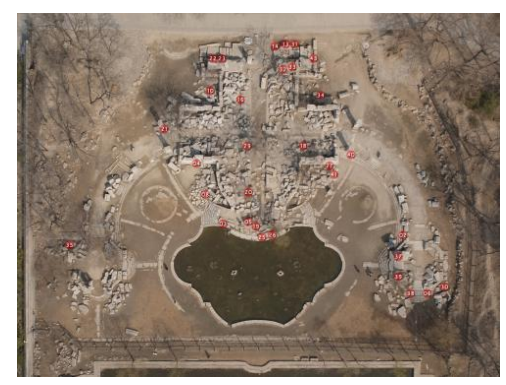

c

Figure 4. Fragment database and location annotation: a. Database; b. Location annotation of fragments on copperplate etching, DaihengGuo and Yan He, 2010; c. Location annotation of fragments on the aerial photograph

The excavation unearthed approximately 300 pieces of glazed components from the archaeological site of Xiyanglou. These fragments were relatively small in size, with different color and dimensions. All the archaeological findings are currently housed in the storage facility of Yuanmingyuan. The initial inventory of the storage identified 80 different styles. Through cross-referencing of the glazed components' surface pattern with the historical photographs, the exact location of 12 pieces of the fragment had been identified. The diversity of style and colour of the decorative components, as well as location restoration of the pieces are shown in the image below. 


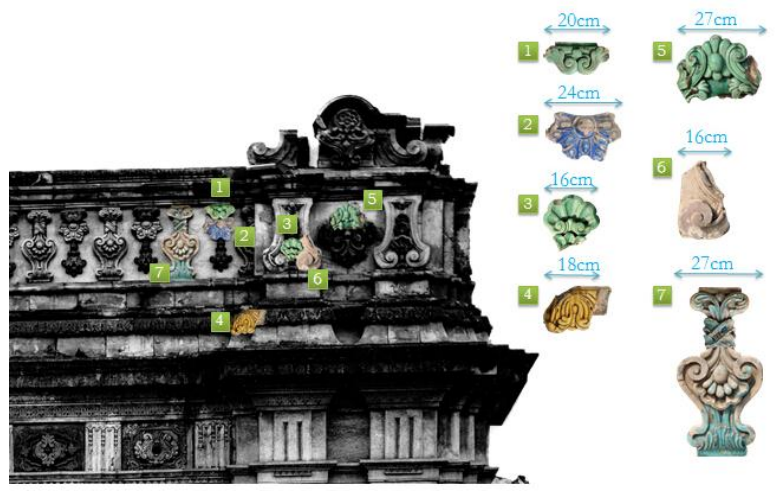

Figure 5. Location restoration of fragments using historic photography, Ernst Ohlmer (1873), 2010

Due to the monochromatic nature of the historical photographs, the preliminary research tended to associate darker parts of the photo with the darker portion on the glazed component and vice versa. However, as more pieces had been linked to their original location on the historical photos, dark blue colour on the fragment was in fact corresponded to the light grey area on the picture, while yellow colour surfaces manifested as dark grey Researchers then observed the colour of the glazed components under the RBG channels in Photoshop. The fragments exhibited no visible colour variation in both Red and Green channel. However, in the Blue channel, the yellow portion of the fragment became dark gray while the blue portion turned light grey, resulted in a condition that was similar to the research finding. So far it is uncertain whether or not this phenomenon is related to the photographic technology back at the time. More research and analysis is required to make a concrete conclusion. Nevertheless, this peculiar discovery did provide useful insight for the colour restoration of historic photos.

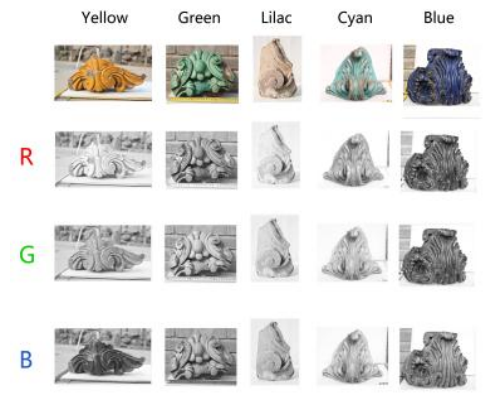

Figure 6. Digital reassessment of colors through Photoshop RBG channels

\subsection{Evaluation of Historical Material}

Due to the severe damage to the site, little were left in Xiyanglou archaeological site for the current-day research. In order to produce a comprehensive digital reconstruction of Xiyanglou, extensive archival research is necessary to support the recording data collected from the site. Sources of reference include historical photographs, copperplate etchings, Yangshi Lei drawing and archival documents. Although abundance of historical material is desirable, discrepancies are inevitable among different referencing sources. Therefore, the restoration research has to combine site recording data, historical resources, and three-dimensional model together, constantly crossreference to ensure the authenticity and accuracy of the information. The following sections elaborate on the method of evaluation and assessment of different types of historical resources.

\subsubsection{Historic Photograph}

There aren't any photo records of Xiyanglou prior to its destruction in 1860. The earliest surviving image of the site was a set of 20 frame photos taken by the German photographer Ernst Ohlmer in 1873. Between 1876 and 1877, Thomas Child and A. Théophile Pir also took some pictures of Xiyanglou. The end of 19th century and the beginning of 20th century saw an increase in the photographic record of the site. Photos from this period featured in relatively liberal shooting angle, recorded the ruins of Xiyanglou at various perspectives at different times of the year. The research team has collected 92 historic photographs up to date.

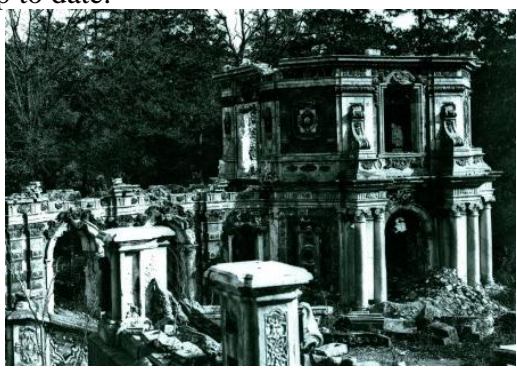

Figure 7. Corridor and music pavilion of Xieqiqu, Ernst Ohlmer (1873), 2010

Historical photographs faithfully record the moment in time, provide significant information to the research studies. However, due to its monochromatic nature, limitation in shooting angles, as well as the deficiency in quantity, historic photographs cannot be the sole reference for the digital reconstruction. Supplementary sources are necessary to draw the reliable conclusion.

For example, based on the following photo, the cornice at the ground floor seems to be at the same level as the corridor and the music pavilion. However, due to perspective distortion and shooting angle, supplementary information is needed to make the conclusion. Therefore, the research team extracted measurements of architectural components collected through site recording. Height of the main building and the music pavilion were then calculated by adding components' dimension from the foundation to the cornice. The height discrepancy among different buildings was $2 \mathrm{~cm}$, proved the height of the main building, the corridor and the music pavilion were at the same horizontal level. 

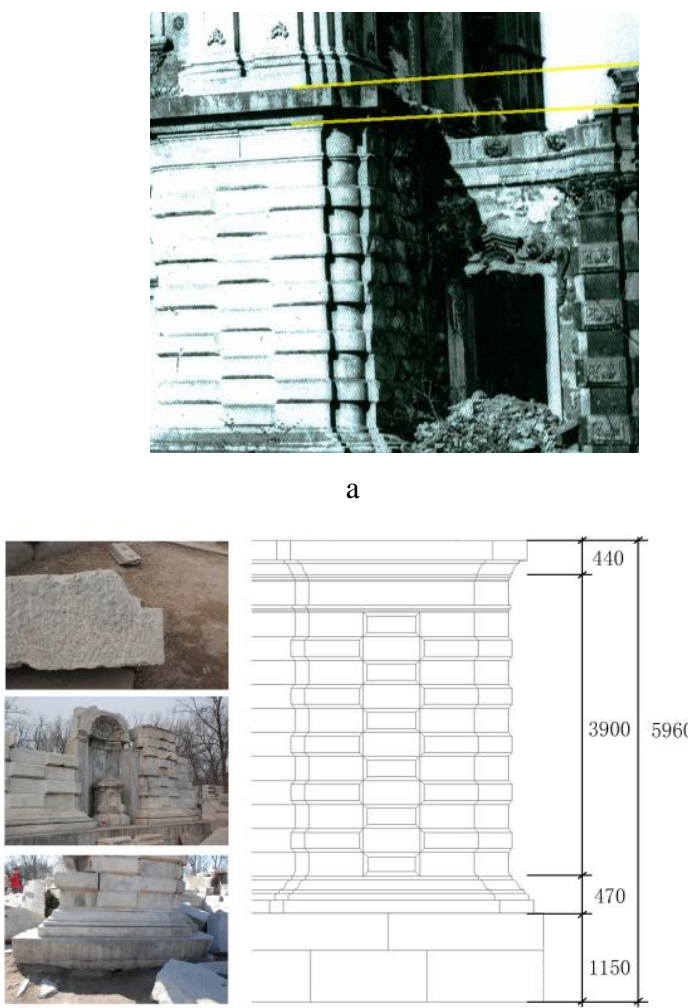

b

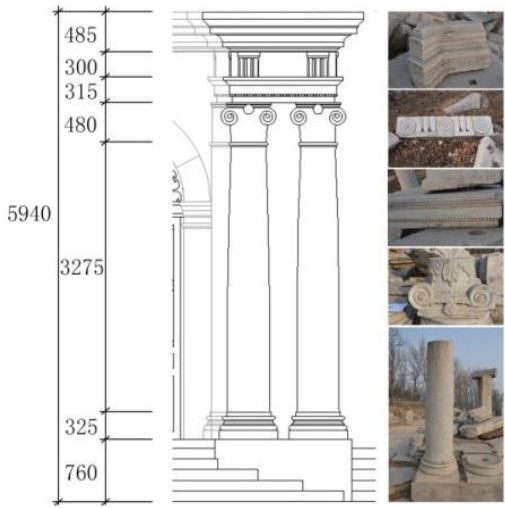

$\mathrm{c}$

Figure 8. Height analysis of the ground floor of Xieqiqu: a. Main building and corridor of Xieqiqu, Ernst Ohlmer (1873), 2010; b. Main building; c. Music pavilion

\subsubsection{Copperplate Etching}

During the construction of Xiyanglou, Western drawing techniques were already known to China. Between 1781 and 1786, a series of 20 copperplate etchings were made under the name of Yuanmingyu Xiyanglou Tongbanhua (Western Buildings of the Old Summer Palace). These drawings provide the closest visual reference to the glorious heyday of the site.

In despite of depicting Xiyanglou in its complete state, research suggests a considerable amount discrepancy between the drawings and the actual building due to experience and technical limitation of the artists. Discrepancies were found between the south façade of Xieqiqu in the copperplates and the historical photographs. Both the site and the photos showed the wall composed of eleven horizontal and three vertical stone slabs while the copperplate indicated something otherwise.

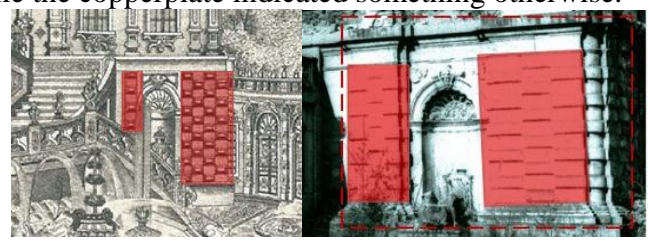

a $\mathrm{b}$

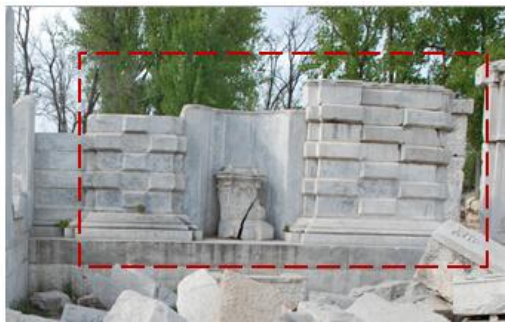

Figure 9. Ground floor façade analysis: a. Copperplate; b. Historic photo; c. Site

\subsubsection{Yangshi Lei drawing (Blueprints drafted by the Lei Family)}

Yangshi Lei drawing presents a holistic overview of architectural composition and layout of the site. Annotation and dimension extracted from the blueprints are crucial for the restoration research. After data cross-referencing, discrepancies were discovered.

The following diagram is the overall site plan of Xieqiqu drafted by the Lei Family. This drawing is the most annotated blueprint known to date, carried more than 120 dimension information when most of the blueprints only contained up to 20 annotations. Many measurements of the northern staircase on the blueprint are different from the measurements collected on site. The foundation of the staircase is relatively intact, without evident of dislocation. Further analysis of the plan reveals traces of modification; indicate that it was a working draft during the design process with a level of uncertainty. Therefore, all researches related to the Yangshi Lei drawing have to be cross-referenced with the on-site condition.

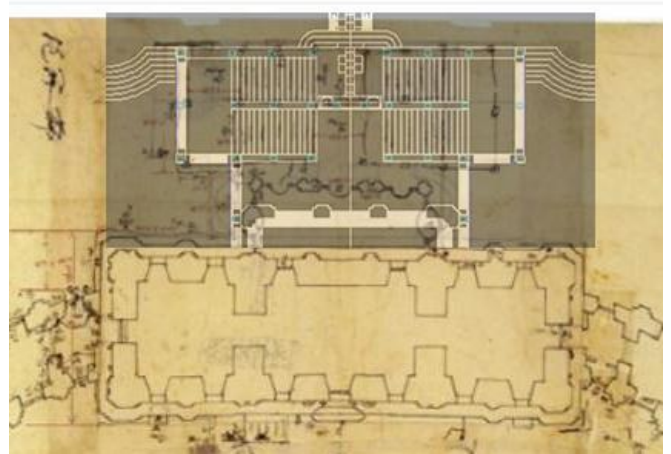

Figure 10. Xieqiqu, floor plan, Yangshi Lei drawing 985, 1744 1751, National Library of China, Yangshi Lei Archive 


\subsubsection{Archival Documents}

The majority of the archival research is based on the Neiwu Fuzao Banchu Gezuo Chengzuo HuojiDang (Project Inventory of Manufacture Department of the Imperial Household Bureau). These documents contain detail records of various architectural restoration, decoration and alteration of Xiyanglou.

Other than Chinese records, research team actively collects relevant information from the foreign sources. Missionaries brought many architectural books from Europe and used them as a reference for the design and construction of Xiyanglou. One notable book was Cour D'architecture by Augustin-Charles d'Avile, a classic handbook that was popular among the European architects. Research indicated close resemblance between some design elements of Xieqiqu and examples in the book. Apart from foreign books, the research team also collects letters of European missionaries at the time, hoping to gain more relevant insight of Xiyanglou from the source.

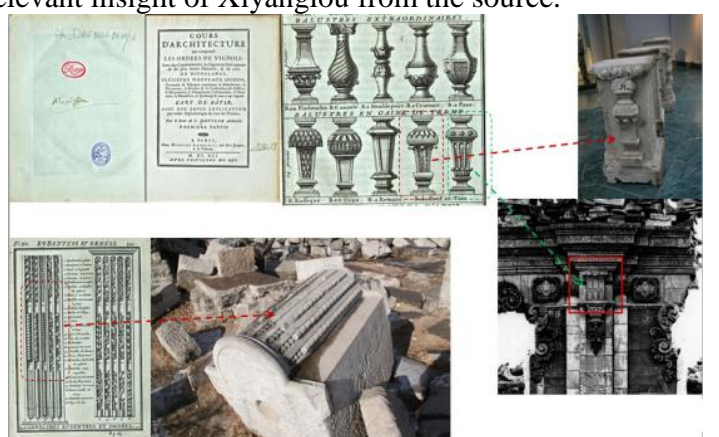

Figure 11. Comparison between examples in foreign architectural treatises and designs of Xiyanglou, AugustinCharles d'Aviler, 1710

\subsubsection{Architectural Ratio Calculation}

Xiyanglou is an architectural fusion between Chinese Qing Dynasty style and Baroque style, constructed using techniques from both the East and the West. Under the circumstances where no references were found from all of the sources mentioned in the previous sections regarding a hybrid component, speculations of the building techniques were made based on the functionality, style and location of the piece. The full dimension of the fragment was calculated based on the conventional ratio in the State Construction Standards of Qing Dynasty and Vignola's collection on Baroque architecture. The calculated dimensions were then matched with the others and cross-referenced with historical resources for its compatibility. The dimension with the best fit was selected as the reference for the digital restoration of the current phase. For other conventional Chinese and Western architectural components, dimensions were calculated based on their corresponded styles.

\section{CONSTRUCTION AND PURPOSE OF THE DIGITAL MODEL}

\subsection{Construction of the Digital Model}

\subsubsection{D Modelling}

Two digital modelling methodologies were deployed to ensure the accurate construction of the digital model, namely CAD based modelling and Point Cloud based modelling.

The former method involving produced a detailed CAD drawing using information from both site recording and historical archival research then imported the drawing into $3 \mathrm{ds}$ MAX to produce the digital model. The accuracy of the digital model was governed by snap to the points and line segments from the CAD reference.

The latter method applies to on-site components that were relatively intact. Point cloud data of the components were collected by the technicians to generate the digital model. Topology technology was used to convert the Dense Cloud high-resolution polygon mesh to a low polygon mesh, in order to optimize the model's performance in the virtual environment while preserved as much detail as possible.

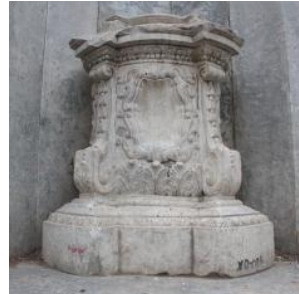

a

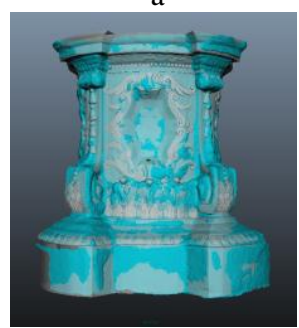

c

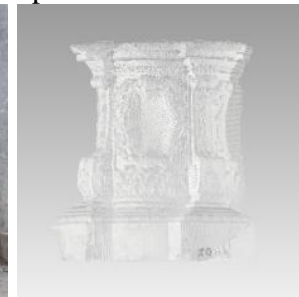

$\mathrm{b}$

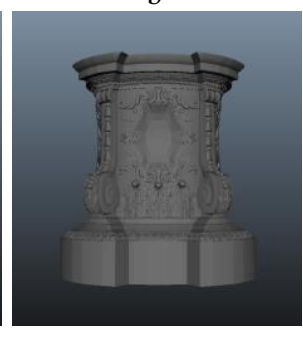

d
Figure 12. a. Element at site; b. Point Cloud data; c. Generating low poly model from high res model using topology technology; d. Low poly model

\subsubsection{Accuracy Assessment for the Digital Restoration}

It is impossible to achieve a hundred percent accuracy in the digital restoration due to the limited source references. Precision can be improved when more information and discoveries gradually surfaced during the research. Assessments were carried out throughout different project phases to properly record the working progress, at the same time provide guidance for future studies.

Considering the complexity of the source references, assessment of different types of data became the foundation of accuracy evaluation of Xiyanglou's digital restoration. Based on the analysis, accuracy of the digital restoration is categorized into four different levels, as illustrated in the table below: 


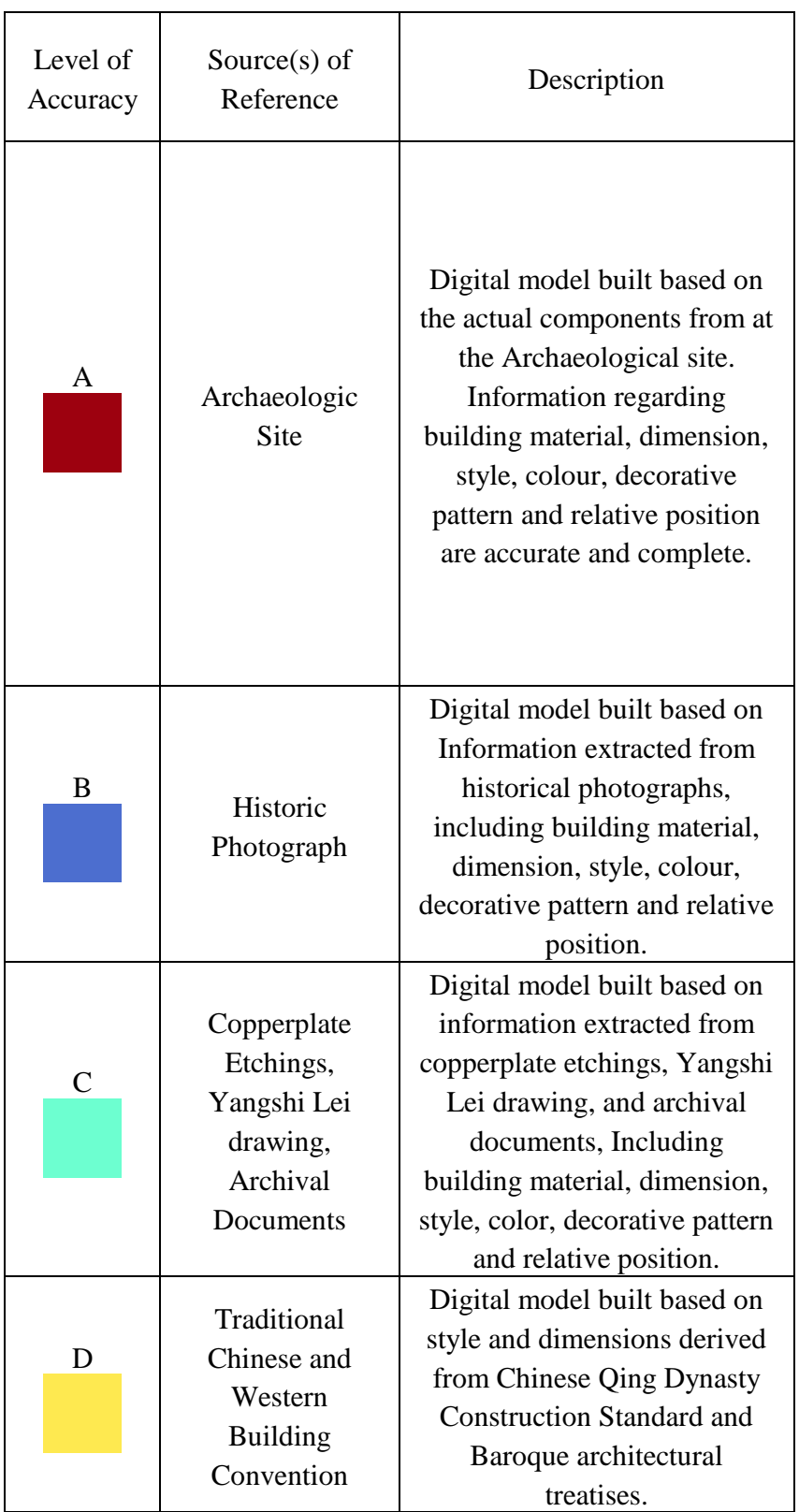

Table 1. Levels of accuracy assessment for the Digital Restoration of Xieqiqu

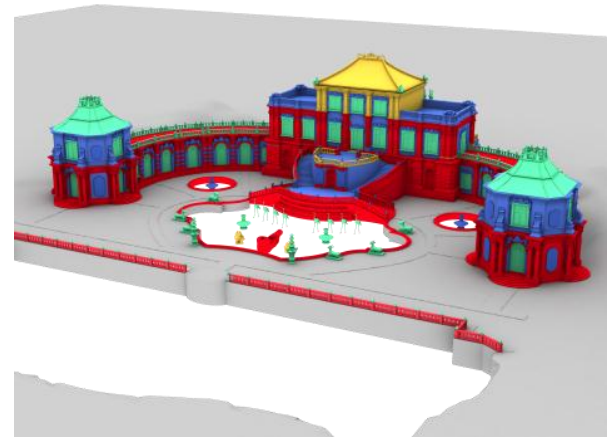

Figure 13. Accuracy assessment for the Digital Restoration of Xieqiqu

\subsection{Application of the Digital Model}

The digital reconstruction model is one of the main achievements in this restoration project. Experimenting and developing the practical applications of the model is the main focus of the future studies.

\subsubsection{Research Aid}

The research achievements are not limited solely to the model. The methodology, progress and phased result of model building accumulated valuable experience and research materials of rich academic merit. The digital 3D models broaden the research dimension by providing a comprehensible visual manifestation for the obscure research data. The virtual 3D environment is not only capable of verifying information that is either unavailable or ambiguous in the historical materials but also allows researchers to assess their findings from a brand new perspective.

\subsubsection{Academic Exchange}

In the field of Heritage Digitalization, the virtual reconstruction project of Xiyanglou attracts many attentions from home and aboard due to the unique architectural and cultural hybrid of the buildings. As one of the most straightforward representation of the project, the $3 \mathrm{~d}$ model becomes the convenient vehicle for academic exchanges among scholars.

\subsubsection{Education, Propagation and Presentation}

Even though the reconstruction research of Yuanmingyuan has yet to be completed, a series of education and cultural dissemination programs had been developed using the virtual model of the site, including the digital mobile guide tablet, Virtual Yanmingyuan APP and "History is FUN" heritage themed summer camp. Numerous publications and cultural by products were made based on the research result of the project. The presentation and propagation of the digital reconstruction are not limited to pictures and videos, dynamic approaches such as the front-projected holographic display, and circular screen experiencing center have already been put on trial. The current research focuses on Augmented Reality and Immersive Virtual Roaming technology.

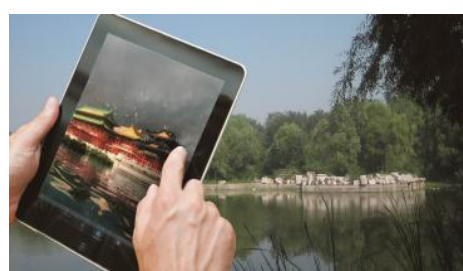

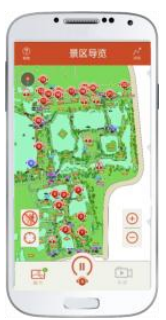

b 


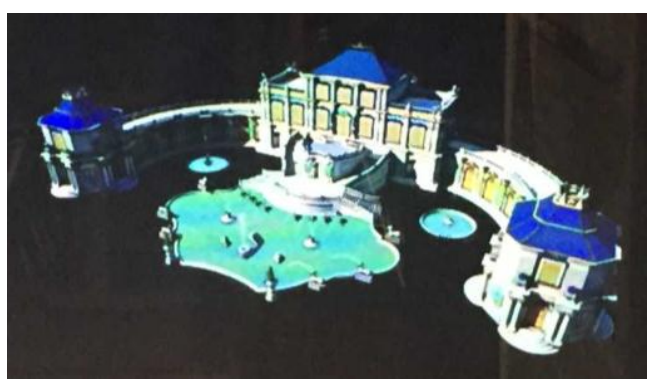

C

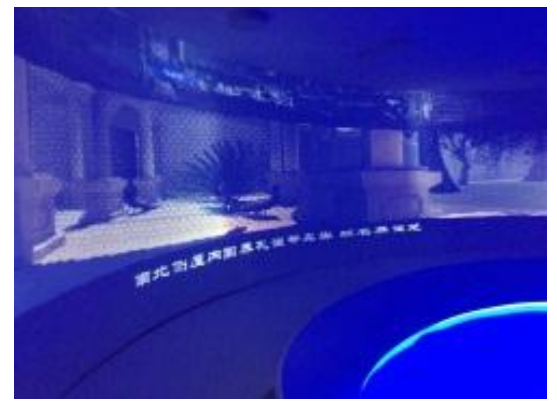

d

Figure 14.a. "Virtual Yanmingyuan"APP; b. Mobile guide; c. Holographic display; d. Circular-screen experiencing center

\section{CONCLUSION}

The digital restoration of Xiyanglou aims to recreate the past glory of the site with the highest historical accuracy possible. The model is based on meticulous site survey and authoritative disciplinary research. The digital reconstruction of Xiyanglou is not based on a linear validation system between the source and the result, but an interrelated data web consists of various types of information. Data extracted from the archaeological site in combination with historical references such as old photographs, copperplate etchings, Yangshi Lei drawing and archival documents, provides an interdependent structure that assures the precision and authenticity of the research result. The 3D model itself has become an important part of the data web for cross-referencing validation. Lessons learned from Xiyanglou Digital Restoration Project not only provide new ideas and new methodologies for heritage conservation but also stimulate the academic exchange and public awareness of cultural heritage.

\section{REFERENCES}

Ernst Ohlmer, 2010, Ernst Ohlmer and Historical Images of Yuanmingyuan (1872-1880), pp. 26-50.

Teng Gu, 1933, Yuanmingyuan Western-Style Building Remnants.

Augustin-Charles d'Aviler, 1710, Cours D'architecture, pp. 301-325.

Huadong Li, 2010, Western Architecture.

Ernest Burden, 1998, Illustrated Dictionary of Architecture.

Bingjian Ma, 1989, Chinese Ancient Architecture Carpentry Techniques.
DaihengGuo and Yan He, 2010, Yuanmingyuan's "Memory Heritage"-Style Drawing File, pp. 552.

Frederique Lemerle and Yves Pauwels, 2008, Baroque Architecture: 1600-1750.

Wenqing Wang, 1999, The Western Classic Orders.

Baroque: Architecture, Sculpture, Painting, 2011, China Railway Publishing House.

Giacomo Barozzi Da Vignola, 2011. Canon of the Five Orders of Architecture

Neiwu Fuzao Banchu Gezuo Chengzuo Huoji Dang, 1747-1783, 369,928 . 